\title{
Relações de poder e disputas territoriais: algumas reflexões sobre políticas de estado e povos indígenas no Baixo Amazonas
}

Territorial disputes and power relations: some reflections on state policies and indigenous peoples in the Lower Amazon

\section{Katiane Silva}

\section{(2) OpenEdition Journals}

\section{Edição electrónica}

URL: https://journals.openedition.org/aa/9308

DOI: $10.4000 /$ aa. 9308

ISSN: 2357-738X

\section{Editora}

Programa de Pós-Graduação em Antropologia Social (UnB)

\section{Edição impressa}

Paginação: 44-65

ISSN: 0102-4302

\section{Refêrencia eletrónica}

Katiane Silva, «Relações de poder e disputas territoriais: algumas reflexões sobre políticas de estado e povos indígenas no Baixo Amazonas», Anuário Antropológico [Online], v.47 n.1 | 2022, posto online no dia 31 janeiro 2022, consultado o 22 julho 2022. URL: http://journals.openedition.org/aa/9308 ; DOI: https://doi.org/10.4000/aa.9308

\section{c.) (i) (9)}

Creative Commons - Atribuição-NãoComercial-SemDerivações 4.0 Internacional - CC BY-NC-ND 4.0 https://creativecommons.org/licenses/by-nc-nd/4.0/ 


\section{Anuário Antropológico}

v.47 n.1 | 2022

2022/v.47 n.1

Relações de poder e resistências indígenas: algumas reflexões sobre disputas territoriais e políticas de Estado no Baixo Amazonas

Power relations and indigenous resistance: some reflections on territorial disputes and state policies in the Lower Amazon

\section{Katiane Silva}

\section{OpenEdition \\ Journals}

\section{Edição electrônica}

URL: http://journals.openedition.org/aa/9308

DOI: $10.4000 / a a .9308$

ISSN: 2357-738X

\section{Editora}

Programa de Pós-Graduação em Antropologia Social (UnB)

\section{Referência eletrônica}

Katiane Silva, «Relações de poder e resistências indígenas: algumas reflexões sobre disputas

territoriais e políticas de Estado no Baixo Amazonas», Anuário Antropológico [Online], v.47 n.1 | 2022.

URL: http://journals.openedition.org/aa/9308; DOI: https://doi.org/10.4000/aa.9308

\section{(c) (i) $(9)$}

Anuário Antropológico is licensed under a Creative Commons. Atribuição-SemDerivações-SemDerivados CC BY-NC-ND 


\title{
Relações de poder e resistências indígenas: algumas reflexões sobre disputas territoriais e políticas de Estado no Baixo Amazonas
}

\author{
Power relations and indigenous resistance: some reflections on territorial disputes and \\ state policies in the Lower Amazon
}

DOI: https://doi.org/10.4000/aa.9308

\author{
Katiane Silva \\ Universidade Federal do Pará, Belém, Pará - Brasil
}

Antropóloga e professora na Faculdade de Ciências Sociais e no Programa de Pós-graduação em Antropologia da Universidade Federal do Pará, Belém, Pará, Brasil.

Este texto tem como objetivo apresentar uma etnografia sobre as relações de poder e de violência contra povos indígenas do Baixo Amazonas. A partir do caso específico sobre a luta e resistência dos Munduruku e dos Apiaká, no Planalto Santareno, no Baixo Amazonas, estado do Pará, apresento reflexões iniciais sobre o problema dos conflitos, a violência e as disputas territoriais na região, a partir de uma perspectiva processual. Essas reflexões são fruto da interlocução com lideranças Munduruku e Apiaká, mediante entrevistas e observação no trabatho de campo, bem como do levantamento de dados bibliográficos e documentais. $\mathrm{O}$ artigo está dividido em três partes e considerações finais. Num primeiro momento, apresento resumidamente o processo de mobilização e a luta do movimento indígena no Baixo Tapajós e no Baixo Amazonas. Na segunda seção do artigo, faço um esboço sobre o tratamento dado pelo poder legislativo local para questões étnicas, tendo como base o caso da criação da "Comissão Especial de Estudos Parlamentares sobre a proliferação de grupos e territórios étnicos no Município de Santarém". Na terceira seção do texto, apresento as situações violentas e as ameaças que os indígenas vêm enfrentando desde a chegada e expansão do agronegócio no seu território.
This paper aims to present an ethnography on power relations and violence against indigenous peoples in the Lower Amazon. Based on a specific case study, which highlights the Munduruku and Apiaká of Santareno Plateau, in the Lower Amazon, state of Pará, I present initial reflections on the conflicts, violence and territorial disputes in this region, from a procedural perspective. These reflections are the result of interactions and discussions with Munduruku and Apiaká leaders, based on interviews and observation made during fieldwork, as a bibliographic review and analysis of documental data. The article is organized into three main sections, in addition to a conclusion. In the first part, I briefly present the process of the struggle and mobilization of the indigenous movement in the Lower Tapajós and Lower Amazon regions. In the second section, I outline the local legislative power given to specific ethnic questions, according to the creation of the "Special Commission for Parliamentary Studies on the proliferation of ethnic groups and territories in the municipality of Santarém". In the third section, I present the violent situations and the threats facing indigenous people since the arrival and expansion of agribusiness in areas pertaining to their territories.

Munduruku and Apiaká of the Santarem Plateau; Amazon; Territory; Power Relations.
Munduruku e Apiaká no Planalto Santareno; Amazônia; Território; Relações de poder.

\footnotetext{
Power Relations.
} 


\section{Introdução}

O objetivo deste texto é apresentar uma etnografia sobre as relações de poder e violência contra povos indígenas do Baixo Amazonas. Essas reflexões, a partir de uma perspectiva processual e histórica da Antropologia ${ }^{1}$, são fruto da interlocução com lideranças Munduruku e Apiaká, mediante entrevistas, conversas informais e observação no trabalho de campo, bem como do levantamento de dados bibliográficos e documentais. Trabalhei também com análise de vídeos, que recebi via redes sociais, produzidos por indígenas, com o objetivo de denunciar as violências que estavam sofrendo em 2018.

O ponto central do texto trata sobre as práticas estatais, a partir de um caso específico da criação de uma Comissão Especial por vereadores de Santarém, com o objetivo de cercear os direitos territoriais de indígenas e quilombolas no município e proporcionar a manutenção do poder e a concentração de terras em certos segmentos econômicos e políticos locais. Analisar essas práticas implica em, segundo Gupta (2015), atentar-se aos contextos múltiplos nos quais o Estado se constitui cotidianamente, por meio de um conjunto de representações e de experiências dos agentes estatais e suas diferentes instituições em relação com o público local.

Segundo Wolf (2003), a palavra poder é carregada de múltiplos sentidos e ao categorizar os diferentes tipos de poder (individual, transacional, tático ou organizacional e estrutural), o autor nos ajuda a compreender, no caso estudado, como a noção de poder estrutural delineia as relações em campo. Essa noção de poder estrutural reflete, de certo modo, as experiências no Planalto Santareno, pois a região tem um histórico de colonização bem demarcado pela violência. Para o autor, essa noção,

é útil precisamente porque nos possibilita delinear como as forças do mundo influenciam os povos que estudamos, sem cair num nativismo antropológico que postula sociedades supostamente isoladas e culturas não contaminadas, seja no presente ou no passado. Não há vantagem num falso romantismo que pretende que "gente real fazendo coisas reais" habita em universos fechados e auto-suficientes (Wolf 2003, 327).

O argumento de Wolf é interessante para analisar a situação que será apresentada, pois a história da região do Baixo Amazonas é caracterizada por diversos processos de exploração dos recursos naturais e da força de trabalho de indígenas e negros que foram escravizados. Destaco aqui dois momentos: a extração da borracha (final do século XIX e início do século XX) e a monocultura da soja como ponto de partida para a análise das práticas de estado e suas implicações nas disputas territoriais locais. A pesquisa documental aponta que essas duas modalidades de utilização e esgotamento dos recursos naturais tiveram o apoio dos governos brasileiros com a premissa de progresso e desenvolvimento da nação ou região, sem considerar ou dar importância à presença de povos indígenas e
1 Trabalhando a partir de um contexto situacional, componho as análises deste texto a partir de experiências vividas em campo e da interlocução com documentos produzidos pelo Estado, tomando como ferramenta analítica as discussões apresentadas por Pacheco de Oliveira (1999). 
tradicionais na região.

O contraponto a esse ideal de progresso como projeto de nação surge com a organização e a articulação dos movimentos indígenas no Baixo Tapajós e no Baixo Amazonas, desde o final dos anos 1990. A compreensão de que "a terra não está aí pra ser comercializada e nem pros grandes empreendimentos”, conforme apontou uma liderança indígena² do Planalto Santareno, é reforçada pelos diversos coletivos, que denunciam e resistem há muito tempo aos empreendimentos estatais: geralmente "os governos apoiam" aqueles que "vêm de fora tomar posse" do território tradicional dos indígenas e que "hoje estão matando as populações com todo esse veneno", completa a liderança ao se referir aos efeitos nocivos do cultivo da soja no Planalto Santareno. Nesse contexto, é importante ressaltar que a violência no cotidiano desses indígenas se concretiza também na palavra sofrimento: o engajamento no movimento representa o risco iminente de sofrer algum ataque violento, já que as ameaças são constantes.

Nos cenários conflituosos do Baixo Amazonas e Baixo Tapajós são acionados diversos mecanismos de estigmatização, racismo e desconfiança com relação aos coletivos indígenas que lutam por seus direitos. As ideias preconcebidas a respeito dos povos indígenas em Santarém validam a violência e são atualizadas conforme a história de exploração da região amazônica, no caso estudado, mediante cultivo da soja. Os desafios enfrentados pelos povos indígenas no Planalto Santareno se intensificam na medida em que a expansão dessa monocultura se estabelece e se afirma cada vez mais com o apoio da política estatal local.

O contexto de Santarém, em termos de políticas para os povos indígenas, é marcado por conflitos agrários, disputas e violência, dentro de uma região caracterizada pela diversidade étnica constantemente ameaçada e que resiste à atuação dos empresários das commodities. Dentre as diversas situações violentas, a expansão da fronteira agrícola no Planalto Santareno, capitaneada pela empresa Cargill, é proveniente do Mato Grosso, com o intuito de escoar grãos, via BR-163. Desde então, há pouco mais de dez anos, os diversos grupos e as terras tradicionalmente ocupadas do território do Planalto têm sido pressionados por empresários do agronegócio.

O artigo está dividido em três partes e considerações finais. Num primeiro momento, apresento resumidamente o processo de mobilização e a luta do movimento indígena no Baixo Tapajós e no Baixo Amazonas. Aqui considero a forte relação entre essas duas regiões, pois observei no campo um complexo de relações históricas, sociais, econômicas e de parentesco. Na segunda seção do artigo, faço um esboço sobre o tratamento dado pelo poder legislativo local para questões étnicas, tendo como base os poucos documentos elaborados a partir da criação da "Comissão especial de estudos parlamentares sobre a proliferação de grupos e territórios étnicos no Município de Santarém”, criada por meio da Portaria ${ }^{\circ} 008$ de 28 de maio de 2019. Na terceira seção do texto, apresento as situações violentas e as ameaças que os indígenas vêm enfrentando desde a chegada e expansão do agronegócio no seu território. Assim, a partir do caso específico sobre a luta dos Munduruku e dos Apiaká, no Planalto Santareno, Baixo Amazonas, estado do Pará,
2 Optei por não informar os nomes das lideranças por motivo de segurança dos interlocutores. 
apresento reflexões iniciais sobre os conflitos, a violência e as disputas territoriais na região.

\section{Contextualizando a luta: alguns apontamentos sobre a organização e a mobilização social indígena no Baixo Tapajós e no Baixo Amazonas}

As experiências de mobilização indígena nas regiões do Baixo Tapajós e Baixo Amazonas podem ser pensadas como processos imbricados, tanto em termos de relação de parentesco (observado nos relatos em trabalho de campo), quanto de organização política e luta por direitos, como foi discutido pela indígena antropóloga Luana Kumaruara (Cardoso 2019). É importante apresentar sucintamente estes movimentos a partir de um cenário específico de construção e consolidação das categorias de unidades de conservação no Baixo Tapajós e as consequências dessas políticas para o próprio movimento indígena. Durante o trabalho de campo, observei a complexidade do processo de ocupação dessas duas regiões que resulta na permanência e na persistência indígena, quilombola e de migração, engendrado por políticas governamentais.

O Baixo Tapajós é uma região caracterizada pela presença de Unidades de Conservação de Uso Sustentável: a Reserva Extrativista (Resex) Tapajós-Arapiuns e a Floresta Nacional (Flona) do Tapajós. A Flona Tapajós foi criada em 1974, mediante Decreto ${ }^{\circ}{ }^{\circ} 73.684$, com o objetivo de promover a exploração racional dos recursos madeireiros e o uso diverso sustentável dos recursos naturais florestais e a pesquisa no âmbito científico. Ioris (2014), ao pesquisar sobre conflitos na Flona Tapajós, verificou que a criação da reserva suscitou desentendimentos entre os moradores que ocupavam aquelas terras há muito tempo. No início de sua implantação, o governo federal forçou o deslocamento populacional, provocando reação contrária aos esforços de conservação.

Em 2001, a antropóloga e indigenista da Fundação Nacional do Índio (Funai) Rita Heloisa de Almeida realizou uma viagem de campo ao rio Tapajós e produziu um relatório em resposta às diversas demandas de estudos antropológicos que vinham surgindo ao longo do rio Tapajós, dentre eles um documento informando o reconhecimento étnico de indígenas Munduruku, Tupinambá e Kumaruara; uma carta redigida no II Encontro dos Povos Indígenas do Tapajós Arapiuns, realizado entre os dias 30 de dezembro de 2000 e $1^{\circ}$ de janeiro de 2001; e uma carta proveniente da comunidade de Bragança e encaminhada ao Ministério Público Federal (MPF) chamando atenção para as invasões do seu território por fazendeiros, madeireiros, posseiros e pescadores provenientes de outras localidades (Funai 2001).

Desde o final da década de 1990, vem ocorrendo um processo de afirmação étnica e luta por direitos territoriais no Baixo Amazonas e no Baixo Tapajós ${ }^{3}$, com o consequente fortalecimento desses movimentos. A resposta estatal para isso foi a tentativa de apagamento da presença étnica, tomando como base os efeitos da burocratização e da classificação que a criação de Unidades de Conservação vem impondo a essas populações. Tomo como exemplo, a persistência do termo "caboclo" em alguns discursos do senso comum político e até mesmo acadêmico. Esse termo geralmente é relacionado a pessoas que vivem no meio rural, como
3 Muito bem discutido nos trabalhos de diversos autores, como loris $(2014,2018,2019)$, Vaz Filho $(2010,2013)$, Peixoto et al. (2012), Lima (2015, 2019), Arantes (2019), e Costa (2019). 
os ribeirinhos, os camponeses e os indígenas, associados a adjetivos pejorativos como ignorantes ou não civilizados pelo mundo moderno, desprovidos de cultura e tidos como atrasados intelectualmente (Lima 1999).

Por muitos anos, os indígenas foram considerados extintos, como um reflexo naturalizado da colonização e exploração territorial local. Os discursos políticos, bem como registros oficiais ou escritos de alguns viajantes (Bates 1979, Smith 1879) fortalecem uma tentativa de apagamento da presença e do protagonismo indígena nos contextos de violência provocados pela expansão colonizadora na Amazônia. A ideia da Amazônia como vazio demográfico pode ser encontrada nesses autores, cujos trabalhos apontam soluções para o que consideram como um problema.

Com o intuito de coletar informações sobre a Amazônia para posteriormente transferir o conhecimento obtido em suas viagens para a comunidade científica internacional, Bates $(1979,139)$ chegou a Santarém em 1851, onde viveu por três anos e meio. Em geral, acompanhado por moradores locais ou mesmo por indígenas que o guiavam nos rios e florestas, o naturalista conseguiu relatar em seu diário, em alguns momentos com bastantes detalhes, os diversos aspectos das sociedades do Baixo Tapajós. Em uma de suas viagens nos arredores de Santarém, ele descreve o lago Maicá (que atualmente passa por uma situação de litígio, com a tentativa de criação de um porto para escoamento de commodities), suas adjacências e a presença de grupos considerados perigosos.

Já o naturalista estadunidense Herbert Huntington Smith visitou a fazenda Taperinha e registrou a presença de indígenas e negros escravizados, além de apontar um projeto colonizador da região: "estou seguro de que as províncias do norte deverão eventualmente ser a maior região agrícola do Brasil, não só por causa de sua produtividade, mas porque estão mais próximas da Europa e da América, os grandes mercados” (Smith 1879 apud Papavero e Overal 2011, 153).

As imagens estereotipadas criadas sobre os indígenas, segundo Roca (2014) ao estudar o trabalho de Rugendas, compõem "um conjunto altamente articulado e persistente de relações históricas de dominação e submissão cultural das populações autóctones, indissoluvelmente ligado ao poder colonial”, intimamente ligadas à trajetória da construção de um projeto de nação específico para o Brasil.

Nesses discursos, os indígenas, ribeirinhos, pequenos produtores ou povos tradicionais eram considerados camponeses ineficientes e culturalmente retrógrados. Suas atividades extrativistas eram consideradas ineficientes e suas produções e seus modos de viver específicos eram desvalorizados (Schmink e Wood 2012). Assim, no empreendimento de colonização, a ideia do pioneirismo dos imigrantes que carregavam a missão civilizadora da região, corrobora, de certo modo, a noção da "última fronteira", conforme apontou Pacheco de Oliveira (2016).

A Resex Tapajós-Arapiuns foi criada mediante o esforço de vários segmentos sociais para a retomada dos territórios cada vez mais ameaçados por madeireiras. Ioris (2014) menciona que o movimento era tão intenso que era necessário "fazer uma varredura”, de acordo com os líderes comunitários. Assim, foram criadas a Associação Intercomunitária Yané Caeté e a Associação Intercomunitárias dos 
rios Aruã, Maró e Arapiuns. Por meio dessas duas associações, as comunidades articularam a criação da Resex Tapajós-Arapiuns em pouco tempo.

A coordenação dos trabalhos de mobilização ficou a cargo de um Grupo de Trabalho, composto por organizações não governamentais, representantes de movimentos sociais, comunitários, representantes do Centro Nacional das Populações Tradicionais (CNPT/IBAMA). Segundo Florêncio Vaz (2013), que acompanhou os trabalhos de perto, "o clima geral era de colaboração num projeto que parecia ser de todos. Até aquele momento, nenhuma comunidade na região do Baixo Tapajós se autoidentificava publicamente como indígena” (id. 145). Assim, a Resex Tapajós-Arapiuns foi oficialmente criada mediante o Decreto de 11 de novembro de 1998, delimitando uma área de aproximadamente 647 mil hectares, abrangendo os municípios de Santarém e Aveiro.

Simultaneamente à criação da Resex, ainda conforme o autor, a comunidade Takuara, localizada na Flona Tapajós (município de Belterra) tornou público seu reconhecimento étnico e reivindicou à Funai a demarcação de suas terras. Se o objetivo inicial do governo com a instituição da Flona Tapajós era promover a exploração dos recursos florestais madeireiros para satisfazer a necessidade do mercado, tal iniciativa não se atentou à presença de comunidades na região, bem como não houve um planejamento ou um estudo prévio para o empreendimento. Isso intensificou os conflitos entre o Estado e as comunidades, pois o maior potencial madeireiro estava concentrado na região onde elas se localizavam.

Por isso, não se pode encarar os conflitos nessa região como fenômenos isolados ou característicos de comportamentos de "povos retrógrados", mas como resultado de novas modalidades de ordenamento territorial, que provocaram uma mudança na realidade e no cotidiano da população local. Portanto, é imprescindível refletir sobre os mecanismos de violação dos direitos indígenas, num cenário no qual a relação entre Estado e esses povos oscila entre a negação e o reconhecimento de direitos (Beltrão 2014). Arrisco ainda a afirmar que o cotidiano dessas pessoas passou a absorver um tipo de burocratização, no qual seus costumes começam a ser regulados pelas leis que regem essas unidades.

Uma das possibilidades percebidas a partir das experiências apresentadas é que ter acesso à terra não significa apenas possuir um bem específico, mas uma possibilidade de reprodução social, cultural, política e econômica. É assumir o compromisso e o protagonismo de sua história - indígena. Deste modo, o sentimento de pertença a um grupo e seus interesses, sejam econômicos ou políticos, é um aspecto da composição da etnicidade em questão. Num espaço onde as fronteiras foram oficial e artificialmente reconfiguradas, diversos grupos étnicos competem por recursos e lidam com as imposições de novos modos de ser ditados pela administração estatal. A identidade indígena em questão também pode ser entendida como uma reconstituição ancestral, cujos identificadores de referência são recriados de acordo com fatores políticos, sociais e o contexto situacional.

As identidades étnicas e as lutas dos indígenas estão relacionadas à força da produção e reprodução das suas práticas culturais, gerando controvérsias com relação ao monopólio administrativo do Estado na gestão de territórios. Percebe-se 
ainda a necessidade, na região, de se estabelecer um modelo de "índio puro", e sua relação com a invenção da tradição, como fundamental no jogo de legitimação social.

Tais situações, que podem ser lidas a partir da chave do racismo estrutural (Almeida 2020) são bastante comuns em diversas regiões brasileiras, e seria impossível discutir boa parte dessas experiências neste espaço. Apesar disso, quero mencionar o caso da resistência dos indígenas Kokama às relações de poder e patronagem também instituídas pelo Estado (Silva 2015), na região do Auati-Paraná, Amazonas, que venho estudando desde 2007; e a experiência da retomada de terras dos Tupinambá na aldeia Serra do Padeiro, Terra Indígena Tupinambá de Olivença (Alarcon 2019). Nesses casos, os indígenas passaram por situações de extrema violência por parte do Estado em nome do desenvolvimento da região.

Os conflitos surgidos a partir dessa forma de afirmação política da identidade estão intimamente relacionados com as disputas prévias nas regiões a serem estudadas, bem como às histórias de desigualdades: relações de patronagem e posse e "grilagem" de terra; fatores religiosos; determinações políticas governamentais, além dos acordos políticos locais. Por isso, é importante compreender o contexto social e histórico dessas regiões e as estratégias dos indígenas para o enfrentamento da violência e tentativa de superação de uma posição de subordinação imposta.

Fanon (1968), ao afirmar que o mundo colonial é um mundo compartimentado, pode ser uma chave de análise para pensar essas novas (ou nem tanto) formas de colonização da Amazônia forçadamente. Um caso exemplar desse processo de "recorte" do território é o da atuação do Instituto Nacional de Colonização e Reforma Agrária (Incra) na região onde está localizado o território dos Apiaká. Segundo uma liderança Apiaká, em 2004 o Incra demarcou assentamentos, sem esclarecer, no entanto, a situação aos Apiaká:

Quando surgiu o assentamento e incluíram todo mundo. Todos nós. Não perguntaram, não tomaram satisfação coisa nenhuma. Eu tava contando que vinham buscar a gente pra uma reunião aqui no Moriá e apareceu um gaiato lá dizendo que nós éramos "índios ressurgidos" e eu disse pra ele que eu tinha conhecimento que ressurgido foi Cristo que ressurgiu dos mortos. [...] Aí tinha um advogado do INCRA e eu disse que ninguém aceitava assentamento (Entrevista com a liderança Apiaká em 2018).

A questão abordada pela liderança, que vive na aldeia de São Pedro do Palhão, no Planalto Santareno, é um desafio constante na região. Em diversas situações, os indígenas são acusados de fraudes, de serem "falsos índios", por não corresponderem às imagens e às representações dos indígenas do período colonial. Essa estratégia foi utilizada pelos políticos durante a CPI da Funai e do Incra ao criminalizar os indígenas por não aparentarem as mesmas características dos indígenas do século XVI (Roca 2019). Na próxima seção do texto será possível analisar um caso específico da ação do Estado em defesa dos interesses empresariais, que implica em formas violentas de classificar e criminalizar os indígenas. 


\section{Estratégias e disputas identitárias: algumas políticas de Estado para povos indígenas e a atuação do legislativo local}

Para o segmento econômico-empresarial santareno, a atuação dos movimentos indígenas no Baixo Tapajós e no Baixo Amazonas representa uma ameaça ao "direito de propriedade privada" e ao desenvolvimento regional. Tal discurso, que persiste em diversas situações, está ligado à ideia de projeto de desenvolvimento para a Amazônia, repercutida em diferentes momentos da história, como, por exemplo, nas políticas de incentivo à presença de imigrantes colonos Confederados em Santarém na segunda metade do século XIX. Outro momento histórico em que podemos observar uma preocupação do Estado com esta ocupação é o período da Ditadura Civil-Militar, apoiada em um conjunto de estratégias para superação do suposto atraso econômico regional, como, por exemplo, a construção da Rodovia Transamazônica BR-230 (Schmink e Wood, 2012) .

Essas articulações para o desenvolvimento não se restringiram ao período ditatorial. A chamada ocupação desordenada da Amazônia, resultante de diversas intervenções estatais, foi um fator decisivo para o avanço na regularização fundiária na Amazônia, com o intuito de atender às necessidades do agronegócio. Menezes (2020) demonstrou que a insegurança jurídica rural sempre foi um obstáculo para o avanço da fronteira agrícola. Neste sentido, os esforços do governo em 2008 se concentraram em uma série de medidas para a elaboração de um programa de desenvolvimento regional, no qual a prioridade era a regularização de grandes áreas de terras públicas. Tais procedimentos resultaram na regulamentação do Programa Terra Legal, lançado em 2009.

Nove anos depois, em dezembro de 2018, o então vereador delegado Jardel Guimarães (PODEMOS), por meio do requerimento $\mathrm{n}^{\circ} 1.819^{5}$, propôs a instauração de uma "Comissão especial de estudos parlamentares sobre a proliferação de grupos e de territórios étnicos no município de Santarém - PA". Tal iniciativa foi motivada, dentre outras situações, pela demanda de representantes do Sindicato Rural de Santarém (Sirsan), assessorados por consultores ${ }^{6}$, com base na ideia de que a existência de territórios indígenas supostamente representa um entrave ao progresso da região.

De fato, as propostas de demarcação de territórios indígenas e quilombolas confrontam os ideais econômicos desses empresários, que aparentemente não medem esforços para arrecadar grandes áreas e expulsar os povos tradicionais de seus locais de origem em nome do crescimento econômico do agronegócio.

Tal ação do legislativo com o advento da "Comissão especial" também pode ser compreendida pela chave de análise das agroestratégias (Almeida 2010), que se caracterizam como estratégias políticas de alianças entre o agronegócio e setores políticos do Estado, com o objetivo e expandir o controle territorial e destituir os direitos territoriais e étnicos de povos indígenas e tradicionais, por meio de alianças nas três esferas de poder (Judiciário, Legislativo e Executivo). De fato, a pressão exercida pelo Sirsan para a criação da "Comissão especial” evidencia essas alianças e as agroestratégias em nível local.

Rosa (2016), ao fazer uma análise sobre "as ofensivas legislativas contra os
4 Schmink e Wood (2012) afirmam ainda que tais estratégias tinham como motivação a resolução das questões políticas da época, já que as autoridades militares e civis adotaram políticas que favoreciam o capital estrangeiro. Foi por meio do projeto Operação Amazônia que os órgãos federais encorajaram investidores brasileiros com créditos e vantagens fiscais para possibilitar a implementação das políticas de desenvolvimento da Amazônia. "Com seu apelo fomentado por temas nacionalistas já consolidados e seu convite ao capital doméstico para participar de uma grande e lucrativa 'aventura da Amazônia' tornou-se um tipo de missão enaltecida, vinculada à grandiosidade da própria nação" (49-50).

5 Disponível no site da Câmara Municipal de Santarém. Fonte: https://sapl.santarem. pa.leg.br/materia/7993. Acesso em: 20 mar. 2020.

6 CARGILL compra soja de fazendas sobrepostas a território indígena em Santarém (PA). De olho nos Ruralistas: observatório do agronegócio no Brasil, 27 out. 2020. Disponível em: https://deolhonosruralistas. com.br/ 2020/10/27/cargill-compra-soja-de-fazendas-sobrepostas-a-territorio-indigena-em-santarem-pa/. Acesso em: 20 de janeiro de 2022. 
direitos indígenas" (184), observa uma centralidade na questão territorial. Concordando com a autora, "são muitos os interesses em disputa com relação à demarcação das terras indígenas" (201) e esses interesses estão pautados na "ideologia do desenvolvimento", segundo a qual se entende que a presença de povos indígenas e tradicionais na Amazônia supostamente representa o atraso para a região, como colocado pelo vereador delegado Jardel Guimarães.

Em postagem de 10 de dezembro de 2018, em rede social, o vereador divulgou a notícia da criação da "Comissão especial":

Na sessão de hoje, apresentamos requerimento visando a criação de uma Comissão Especial de Estudos Parlamentares sobre a proliferação de grupos e territórios étnicos em nosso município. Esse aumento de grupos que se autodenominam "indígenas" e "Quilombolas" vem crescendo assustadoramente, e com isso afetando o desenvolvimento econômico de nossa cidade?

É importante observar o posicionamento e a ação política de parte dos vereadores de Santarém durante a legislatura compreendida entre 2017 e 2020, e sua parceria com os setores empresariais. A criação da "Comissão especial" pode ser observada como um exemplo para compreendermos as formulações para proposições dos projetos de nação, das práticas de estado, aqui representadas principalmente pelo agronegócio como um ator e articulador de pautas legislativas, como observou Almeida (2010), com o conceito de agroestratégias. De fato, essas alianças e articulações não são novas, elas fazem parte não apenas do complexo processo de colonização local, mas de diversos programas de governo.

Apesar dos esforços do vereador em atender ao pedido dos empresários do agronegócio, não houve celeridade no processo de instalação da Comissão. Na sessão ordinária de 16 de abril de 2019, o vereador cobrou dos colegas providências para a efetivação do processo:

O vereador DEL. JARDEL GUIMARÃES (PODE) recordou que no final do período legislativo do ano passado, a Casa aprovou uma solicitação do Sindicato Rural de Santarém - SIRSAN, que requeria a criação de comissão especial de estudo sobre a proliferação de grupos e territórios étnicos no município. Segundo ele, tal requerimento foi devidamente aprovado e imediatamente o denominaram como membro da comissão, juntamente com os vereadores Dayan Serique e Júnior Tapajós. Contudo, também faziam parte Henderson Pinto, atual secretário de Estado e Silvio Amorim, que já não faz parte dessa legislatura. Disse que o SIRSAN requereu que seja instalado tal comissão; por isso, solicitou à Mesa Diretora que dê celeridade ao pedido (Santarém 2019a, 1).

O discurso do vereador demonstra claramente a pressão exercida pelo Sirsan sobre os vereadores. No entanto, somente após cinco meses da aprovação do re-
7 Disponível no link: https://www.facebook. com/delegadojardel.1/ posts/2292866030945598. Acesso em 20 de março de 2020. 
querimento n ${ }^{\circ} 1.819 / 18$, a "Comissão especial" foi criada mediante a Portaria $\mathrm{n}^{\circ}$ 008, de 28 de maio de 2019, com caráter temporário e duração de 120 dias. Sua composição foi instituída pela Portaria ${ }^{\circ}$ 010, de 03 de junho de 2019, com os seguintes vereadores: Alaércio Magalhães Cardoso (Partido Republicano Progressista - PRP), como presidente; Dayan Serique dos Santos (Partido Popular Socialista - PPS $^{8}$ ); Jackson Douglas Santana Ferreira (Partido Social Liberal - PSL); Francisco Sousa (Partido da Social Democracia Brasileira - PSDB); e Rogélio Cebuliski (Partido Socialista Brasileiro - PSB).

$\mathrm{Na}$ ata da quadragésima sessão ordinária da câmara de vereadores de Santarém, de 3 de junho de $2019^{9}$, o vereador Chiquinho (PMDB) enfatiza sua preocupação com os trabalhos do Grupo Técnico, conhecido como GT Munduruku e Apiaká do Planalto Santareno. O GT foi constituído pela Funai por meio da Portaria $\mathrm{n}^{\circ}$ 1.387, de 24 de outubro de $2018^{10}$, com o objetivo de responder ao Termo de Conciliação Judicial homologado no Processo no 1000141-38.2018.4.01.3902 e à Ação Civil Pública no 1912/2018, proposta pelo Ministério Público Federal, que "em desfavor da UNIÃO e da Funai, visa sanar injustificada e reiterada omissão dos réus em adotar medidas administrativas necessárias à identificação e à delimitação do território do povo indígena Munduruku, no município de Santarém/PA" (Ministério Público Federal 2018, 2). A finalidade do Grupo, portanto, era realizar os estudos necessários à identificação e delimitação da área demandada pelos indígenas Munduruku e Apiaká que ocupam o território do Planalto Santareno. Segundo a ata da sessão, o então vereador Chiquinho comentou que:

uma equipe da Funai de posse de uma portaria de 2018, estaria fazendo estudo para criação de área indígena naquela região. Ressaltou uma preocupação, pois, de acordo com o parlamentar, é uma área já consolidada por agricultores. Disse que a Casa não vai ficar de braços cruzados, e estará se mobilizando com os moradores da região e Executivo para que, junto ao novo presidente da Funai e Governo Federal, tratem sobre a questão (Santarém 2019b, 1).

Continuando o debate, o então vereador Rogélio Cebulisk, conhecido como Gaúcho, reforçou a preocupação, alegando que "a Casa precisa acompanhar a situação" e justificou a ausência na próxima sessão, pois estaria em "uma reunião com o presidente da Funai e outras entidades, em que faz questão de participar e mostrar indignação quanto a esse processo" (Santarém 2019b, 2). Aqui ele se refere especificamente ao primeiro trabalho de campo realizado em maio de 2019 pelo GT Munduruku e Apiaká do Planalto Santareno, dando início aos estudos para o processo de identificação e demarcação da terra indígena pleiteada pelos indígenas. Em seguida, o vereador Alaércio Magalhães, em resposta a essa suposta "ameaça" da Funai, destacou a Portaria de composição da "Comissão especial" de estudos parlamentares, enfatizando o comprometimento desses vereadores com os segmentos econômicos empresariais da região.

Em um contexto aparentemente dominado pelas orientações do governo
8 Em setembro de 2019, o Tribunal Superior Eleitoral (TSE) aprovou a mudança do nome do Partido Popular Socialista (PPS) para Cidadania.

9 Disponível no site da Câmara Municipal de Santarém: https://sapl.santarem.pa.leg.br/ materia/10141. Acesso em 20 de março de 2020.

10 A Ação está disponível em: http://www.mpf.mp.br/ pa/sala-de-imprensa/documentos/2018/acao_mpf_ identificacao_delimitacao_territorio_munduruku_planalto_ santareno_pa_maio_2018.pdf/ view. Acesso em 20 mar. 2020. 
federal, que naquele momento se posicionava totalmente contrário aos direitos territoriais de indígenas e quilombolas, os vereadores defendiam os interesses ruralistas, com a justificativa do apoio ao desenvolvimento da região, e demonstravam naquela sessão indignação com a realização do trabalho de campo do GT.

Embora diversos setores do Estado estivessem trabalhando nesta perspectiva, outros segmentos se comprometeram com a defesa dos direitos indígenas, como, por exemplo, no caso da atuação de alguns servidores do MPF em Santarém, que pressionaram a presidência da Funai a providenciar o início dos estudos no Planalto Santareno, evidenciando as contradições e as multiplicidades das práticas estatais.

Os destaques e as indignações dos parlamentares chamam atenção para o reforço de uma suposta ocupação consolidada no Planalto Santareno por agricultores não indígenas, ignorando totalmente a presença de indígenas e de quilombolas na região. Além disso, aponta para os esforços de articulação entre empresários e políticos com o objetivo de pressionar instituições, como a Funai, bem como a diversidade étnica regional.

De acordo com uma jovem liderança representante do Conselho Indígena Tapajós Arapiuns (Cita), os indígenas tiveram acesso a essas informações com certa demora. Em reação a criação da "Comissão especial”, as lideranças indígenas do Baixo Tapajós junto ao Cita se reuniram com o então prefeito Nélio Aguiar e em outras oportunidades conversaram com alguns vereadores membros da Comissão, como o vereador Jardel Guimarães no sentido de frear os ataques aos indígenas e quilombolas. $\mathrm{O}$ teor dos diálogos era tenso, pois as lideranças pressionaram os vereadores a extinguir a "Comissão Especial”; caso contrário, o Cita moveria um processo via MPF contra a Câmara Municipal alegando racismo estrutural.

Ainda conforme a liderança, o vereador Delegado Jardel tentou aproximação com ela via redes sociais, em outubro de 2019. A liderança afirmou estar surpresa, já que o vereador iniciou os processos e se tornou membro da Comissão. $O$ vereador respondeu que retirou seu nome da Comissão devido à condução dos trabalhos. A liderança respondeu que "a Comissão tem um formato racista" e que ficou em dúvida a respeito da aproximação do vereador, se "era bem ou mal intencionada".

Os anos de 2018 e 2019 transcorreram sob grande tensão no Baixo Amazonas, tanto para os indígenas quanto para os quilombolas. Os embates com representantes do agronegócio se tornaram mais frequentes e, além disso, o cenário político e governamental se configurou de modo desfavorável aos grupos étnicos locais. Foi nesse contexto de transformações sociais e políticas drásticas no Brasil, da ascensão da extrema-direita ao poder, com a diminuição dos direitos sociais e a criminalização dos direitos humanos, que os coletivos indígenas do Baixo Rio Amazonas e do Baixo Rio Tapajós se posicionaram contrariamente à maior abertura da Amazônia como a última fronteira do agronegócio.

Durante sua campanha política de 2018, o então candidato à presidência da República Jair Bolsonaro reforçou o discurso de combate aos movimentos sociais, direitos humanos e às minorias sociais, em especial, aos indígenas e quilombo- 
las. O candidato chegou a afirmar em entrevistas antes e pós-eleição que "no que depender de mim, não tem mais demarcação de terra indígena"11. Essa postura fomentou na região a sensação de que o agronegócio dominaria toda a economia local, e os territórios indígenas seriam anulados.

Um mês antes da instauração da Comissão Especial e poucas semanas após as eleições de 2018, em 8 de novembro de 2018, a Comissão Interamericana de Direitos Humanos (CIDH), órgão ligado à Organização dos Estados Americanos (OEA), visitou a aldeia Açaizal no Planalto Santareno ${ }^{12}$, com o propósito de ouvir os testemunhos de indígenas e quilombolas e registrar as situações de ameaças e conflitos agrários na região. Os participantes da reunião - dentre os quais, membros das comunidades indígenas e quilombolas de Santarém, de organizações não governamentais e do Estado - foram surpreendidos com a chegada de um grupo de representantes do Sirsan. Na ocasião, os membros da CIDH e os participantes presenciaram a ação intimidadora de alguns representantes dos interesses dos “sojeiros ${ }^{13}$ ", que exigiam participação na reunião.

Conforme um vídeo divulgado pelas mídias sociais ${ }^{14}$, uma jovem liderança Munduruku explicou que enquanto eles aguardavam o início da reunião, os representantes dos "sojeiros" chegaram "para tumultuar a reunião” e, inclusive, "agrediram uma das nossas lideranças (...) ele bateu no celular dela, derrubou no chão e isso é uma forma muito grosseira em um momento muito tenso, que culminou com a saída deles posteriormente com a chegada da polícia”. Dias após a agressão, ela registrou Boletim de Ocorrência, entretanto nada foi apurado até o momento, conforme relato da indígena.

A ação intimidadora transcorreu desde o ato de seguir a comissão, fotografar as placas dos veículos estacionados próximos ao barracão da aldeia Açaizal, até abordar um dos membros da CIDH, argumentando que a Convenção 169 da Organização Internacional do Trabalho (OIT) era um equívoco para a nação brasileira, pois na região em questão não existiam índios. Em resposta, o comissário alegou que "fomos convidados pelo Estado, temos autonomia internacional e nos reunimos com quem queremos”15. Somente após a chegada e a intervenção da Polícia Federal, a reunião foi iniciada.

Em comunicado à imprensa de 12 de novembro de 2018, publicado no site da $\mathrm{OEA}^{16}$, os membros da CIDH enumeram 26 pontos importantes e preocupantes observados nas reuniões realizadas por todo o país. Dentre eles, no $18^{\circ}$ ponto chamam atenção para "situações urgentes", que tratam das violações de direitos de indígenas e quilombolas. Nesse ponto destacam "obstáculos crescentes para a demarcação de suas terras e dificuldades apresentadas pela tese do marco temporal" e expõem o que vivenciaram na reunião:

Também a comunidade indígena da Aldeia de Açaizal em Santarém/Pará que está submetida a práticas de coerção, ameaças e tentativas de intimidações por exercer o direito de defender seus direitos. A esse respeito, a CIDH deseja registrar publicamente que não só recebeu denúncias sobre essas práticas, como também foi alvo direto de intimidação na localidade (CIDH 2018b).
11 "No que depender de mim, não tem mais demarcação de terra indígena", diz Bolsonaro a tv. Folha de São Paulo, São Paulo, 05 nov. 2018. Disponível em: https://www1.folha. uol.com.br/poder/2018/11/ no-que-depender-de-mim-nao-tem-mais-demarcacao-de-terra-indigena-diz-bolsonaro-a-tv. shtml. Acesso em: 20 dez. 2021.

12 Esta visita foi possível mediante convite do Estado brasileiro em novembro de 2017 e tinha como objetivo "observar a situação dos direitos humanos no país" (CIDH 2018a, 1). A viagem ocorreu entre os dias 5 e 12 de novembro de 2018 , a comissão foi formada por seis equipes que se dividiram pelo Brasil e as observações preliminares sobre a viagem foram publicadas em um relatório disponível no site: https://www. oas.org/es/ cidh/prensa/comunicados/2018/2380Pport.pdf. Acesso em: 12 abr. 2020.

13 As categorias "sojeiro" e "gaúcho", utilizadas pelos interlocutores da pesquisa, podem ser consideradas sinônimos. 0 sojeiro é como os interlocutores se referem aos produtores de soja. A categoria "gaúcho", de modo geral, é utilizada pelas populações amazônicas para se referir aos migrantes do sul do país e de outros estados, como o Mato Grosso.

14 Fonte: transcrição de trecho de um vídeo gravado por lideranças indígenas em 08 de novembro de 2018 e compartilhado via WhatsApp em dezembro de 2018.

15 Fonte: transcrição de trecho de um vídeo recebido pela autora em dezembro de 2018, via aplicativo WhatsApp, gravado por liderança indígena em 8 de novembro de 2018.

16 Disponível em: https:// www.oas.org/pt/cidh/prensa/ notas/2018/238.asp. Acesso em: 20 mar. 2020. 
Após ouvir os depoimentos e as histórias que os indígenas vêm enfrentando ao longo de muitos anos, no discurso final, os membros da CIDH demonstraram preocupação com o que testemunharam e informaram que a visita teria como produto um relatório ${ }^{17}$ com recomendações ao Estado brasileiro a fim de que cumpra com suas obrigações internacionais para com os direitos humanos.

A criação dessa “Comissão especial de estudos parlamentares”, em 2019, pode ser entendida, a princípio, como uma resposta do poder legislativo de Santarém à demanda de empresários do agronegócio contrários à demarcação de territórios indígenas e quilombolas. Os mesmos representantes que invadiram a reunião da CIDH apresentaram a demanda à Câmara. Nesse sentido, o cenário é marcado por disputas também político-partidárias que se alinham ao empresariado local; o que está em jogo ainda é a construção de um projeto de nação carregado pela história de violência que marca a colonização brasileira.

Embora os indígenas e seus aliados estivessem apreensivos com a composição e o teor dessa "Comissão Especial", não foi possível encontrar documentos nos canais oficiais que comprovassem uma atuação efetiva dos vereadores na "Comissão". Aparentemente, a investigação dos vereadores sobre a "proliferação de grupos étnicos" em Santarém tinha um objetivo específico: acompanhar os trabalhos do GT Munduruku e Apiaká do Planalto Santareno.

O único registro encontrado no site da câmara municipal de Santarém sobre a atuação da "Comissão Especial" foi a prestação de contas da viagem do vereador Chiquinho a Brasília (Distrito Federal) para se reunir com o então presidente da Funai e outros políticos a fim de tratarem dos assuntos relacionados aos indígenas. Conforme a ata da décima segunda sessão ordinária, realizada no dia 9 de setembro de 2019,

o vereador CHIQUINHO (PSDB) prestou contas da viagem a Brasília da comissão de estudo da Casa que acompanha a criação e proliferação de grupos indígenas no município. Estiveram participando de uma reunião com o Presidente da Fundação Nacional do índio - Funai e a Diretora de Proteção Territorial, Silmara Veiga, com a finalidade de obter melhores esclarecimentos sobre a forma como está sendo criada alguns territórios do planalto Santareno. Disse que a indagação foi a portaria que foi esclarecida pelos membros da instituição. Informou que a Casa vai encaminhar um documento, enfatizando que não são contra, mas precisam estar informados da situação.

(...)

O vereador ALAÉRCIO DROGAMIL (PRP) registrou sobre a viagem da comissão que trata da proliferação de grupos e territórios étnicos no município de Santarém a Brasília, onde aconteceu uma reunião com o Presidente da Funai com a participação da Diretora de Proteção Territorial, Silmara Veiga. Relatou que, o objetivo da reunião foi para entender a portaria e a partir disso fazer encaminhamentos a fundação. Segundo ele, a Casa tem o dever de ser informada sobre essa problemática. Informou que deve ser marcada
17 Disponível em: https://www. oas.org/es/cidh/prensa/comunicados/2018/2380Pport.pdf. Acesso em: 20 de março de 2020 . 
em Brasília em que o prefeito Nélio Aguiar deverá participar (Santarém, 2019c, 1-2).

É claro no registro em ata que a preocupação dos vereadores aparentemente é fiscalizar o processo demarcatório do território reivindicado pelos Munduruku e Apiaká no Planalto Santareno. A notícia da reunião foi publicada no site da câmara dos vereadores ${ }^{18}$ e informa que os vereadores Chiquinho, Alaércio Cardoso e Rogélio Cebuliski estiveram reunidos com representantes do Sirsan e com o presidente e com a diretora de proteção territorial da Funai. Além disso, os vereadores e os representantes dos produtores rurais do Planalto Santareno também estiveram reunidos com o então deputado federal Júnior Ferrari. A viagem também foi divulgada em uma rede social da câmara municipal de Santarém, em postagem de 6 de setembro de 2016, intitulada "Comissão de vereadores discute territórios étnicos na Funai". No texto, a assessoria de imprensa reforça o objetivo da comitiva formada por vereadores, empresários do agronegócio e representantes do Sirsan: tratar "da proliferação de grupos e territórios étnicos no município de Santarém"19.

Após seis meses de criação, a "Comissão Especial" é extinta mediante a Portaria número 012, de 20 de novembro de 2019. O relatório da comissão não está disponível no site da Câmara Municipal de Santarém. Dentre as várias questões que surgem a partir da análise da criação da comissão, o que chama atenção é a utilização de mecanismos do Estado para organizar o "grande cerco" do agronegócio em torno dos territórios indígenas. A presença e as resistências indígenas incomodam esses empresários, pois a reivindicação de demarcação de territórios representa não apenas a proteção do meio ambiente, mas a reprodução de práticas culturais que antagonizam com o atual projeto de nação colocado em prática por diversos governos brasileiros.

\section{As experiências dos Munduruku e dos Apiaká no Planalto Santareno frente ao "grande cerco" da soja}

O território ocupado e vivido pelos Munduruku trata-se de quatro aldeias: Ipaupixuna, Açaizal, São Francisco da Cavada e Amparador. Possui uma população estimada em 607 indígenas, que passaram por diversas situações violentas e deslocamentos compulsórios em um território que se estende desde o Médio rio Tapajós até o Baixo rio Amazonas, onde se fixaram na região conhecida como Planalto Santareno. Tal região abrange áreas dos municípios de Santarém, Belterra e Mojuí dos Campos.

Os Apiaká vivem às margens do Rio Curuá-Una, na Aldeia de São Pedro do Palhão, onde estão presentes desde meados da década de 1950, quando chegaram na região por meio do deslocamento compulsório pelo qual passaram em decorrência do trabalho em seringais da Amazônia. As famílias dos Apiaká foram trazidas por seringalistas de Santarém que os recrutaram compulsoriamente em aldeias do Mato Grosso. Pouco tempo depois, essas famílias foram abandonadas pelos seringalistas e permaneceram na região, criando a aldeia de São Pedro do Palhão. Mais tarde, a aldeia de São Pedro sofreu os impactos e os efeitos sociais
18 Disponível em: https:// santarem.pa.leg.br/comissao-discutiu-sobre-territorios-etnicos-no-municipio-de-santarem/

19 Disponível em: https://www. facebook.com/camarasantarem/ posts/2455973258006403. Acesso em: 15 de março de 2020. 
da Hidrelétrica de Curuá-Una, construída na década de 1970.

Os Munduruku e os Apiaká estão se organizando na luta pelo território desde a primeira metade dos anos 2000 e vêm provocando a Funai para a realização dos estudos de identificação do território indígena. São representados pelo Conselho Indígena Munduruku e Apiaká do Planalto Santareno, criado em 2009, com o apoio do Cita e do Conselho Indigenista Missionário (Cimi). A inclusão dos Apiaká no Conselho faz parte do processo histórico de parceria entre esses dois povos na luta pela permanência no território. Ambos os povos vêm enfrentando a expansão da fronteira agrícola no Planalto Santareno, que se intensificou com o estabelecimento de um porto administrado pela empresa multinacional Cargill, que escoa grãos, via BR-163. Desde então, há cerca de 10 anos, as aldeias do território do Planalto têm sido pressionadas por empresários do agronegócio.

A constituição da "Comissão especial" não impediu a campanha política desses vereadores no Planalto nas eleições municipais de 2020. Conforme uma liderança indígena, em entrevista no Planalto, alguns candidatos que concorriam à reeleição foram a sua casa "pedir votos", mas, ao recebê-los, argumentou que não votaria neles, pois estavam envolvidos na articulação da "Comissão especial”, portanto, eram "anti-indígenas".

As experiências vividas pelos Munduruku e Apiaká podem ser compreendidas como experiência colonial compartilhada a partir das estruturas de poder presentes na região, que se ramificam na história, economia e política local (O’Dwyer e Silva 2020). Tal experiência se concretiza em estratégias de domínio e domesticação do território do Baixo Amazonas, capitaneado por programas de governo. Aqui destaco as situações de exploração da borracha (final do século XIX e início do século XX), as construções das rodovias Transamazônica (BR-230) e Cuiabá-Santarém (BR-163) e, mais tarde, grandes empreendimentos e projetos agropecuários. Esses empreendimentos tiveram e ainda têm o apoio dos governos brasileiros com a premissa do progresso e desenvolvimento, sem considerar ou dar importância à presença de povos indígenas e tradicionais na região.

Conforme Costa (2012), a monocultura da soja foi introduzida no Pará na década de 1990, mediante projetos implementados no Plano Operacional de Política Agrícola “Pará Rural”. A partir da ideia de Polos de Desenvolvimento, o governo estadual efetivou três Polos com a produção da soja: o Polo Agroindustrial do Sudeste Paraense, o Polo Agroindustrial e Agroflorestal do Oeste Paraense, e o Polo Agroindustrial do Nordeste Paraense. Essas áreas de plantio foram estruturadas nos municípios de Redenção, Santarém e Paragominas.

O Governo do Pará contratou os serviços da Agrária Engenharia Consultoria S.A., em 1996, para realizar estudos sobre as possibilidades da instituição da agricultura empresarial em Santarém. Com resultados positivos, em 1997, chegaram à região os primeiros sojicultores oriundos das regiões sul do Mato Grosso e de Roraima (Costa 2010).

Conforme relatos de uma jovem liderança Munduruku, os indígenas notaram a chegada dos sojicultores, não a vendo, de início, com preocupação, pois se tratava de pequenos e médios produtores e havia muitas áreas com floresta. Conforme 
o tempo passou, o território indígena foi gradativamente sendo ocupado pelos "sojeiros", que foram implementando seus empreendimentos e, inicialmente, não impediam o livre trânsito dos indígenas no território. Conforme os grandes empresários foram chegando, eles passaram a "se apossar do nosso território, eles passaram a impedir o uso desse território que sempre foi nosso", conforme relatou a liderança. Em consequência da tomada do território, as árvores começaram a ser derrubadas e foram substituídas por plantações de soja, as caças foram desaparecendo; os solos começaram a ser encharcados com veneno dos agrotóxicos e os indígenas foram cercados por essas plantações.

Em 1999, iniciou-se a instalação da empresa multinacional Cargill e, mesmo ganhando licitação pública para operação, seu estabelecimento não ocorreu de forma facilitada. Houve muita resistência, "envolvendo ações judiciais, intensa mobilização social dos movimentos sociais locais e de ONGs ambientalistas com atuação internacional" (Costa 2012, 209). Os sojicultores presentes no território Munduruku adquiriram as terras pela compra e negociação com famílias da elite santarena e a partir protocolos do Programa Terra Legal (Terra de Direitos, 2015).

Steward (2007) já havia chamado atenção para a forte relação entre os governos local e federal e empresários do agronegócio a fim de promover uma espécie de desenvolvimento agroindustrial para Santarém. Segundo a autora, representantes da sucursal da empresa Cargill, em Santarém, defendem o desenvolvimento do agronegócio como o modelo ideal de atividade econômica para a região. Nesse contexto ideal, o papel dos produtores de soja é fazer a conexão entre as agendas nacional e local do desenvolvimento. Embora esses empresários se considerem "heróis nacionais", ainda conforme esta autora, o cultivo da soja implica em consequências danosas às vidas das pessoas e ao território.

A aldeia de Açaizal, por exemplo, vem sofrendo desde 2004 com o assoreamento de seu igarapé e com o envenenamento de nascentes por agrotóxicos. Os Munduruku solicitaram a presença de órgãos como o Instituto Brasileiro do Meio Ambiente e dos Recursos Naturais Renováveis (Ibama) e Incra para que solucionassem a situação, mas não houve uma resolução efetiva. Em 2019, o MPF impetrou uma Ação Civil Pública ${ }^{20}$ em desfavor do estado do Pará e do município de Santarém com o objetivo de interromper a degradação do igarapé do Açaizal e a recuperação dos danos causados pelo constante uso de agrotóxico nas lavouras de soja.

Outra situação que preocupa os indígenas e que está intimamente ligada ao discurso de desenvolvimento local, é a tentativa de construção de um porto de escoamento de grãos (local e de outros estados) no Lago do Maicá, localizado na região estudada. A Empresa Brasileira de Portos de Santarém (Embraps) capitaneou este processo e, desde 2013, vem travando embates com as lideranças do Baixo Amazonas e Baixo Tapajós para a construção do Porto do Maicá (Del Arco 2017). Em sentença de 5 de outubro de 2019, a Justiça Federal proibiu a continuidade dos procedimentos de construção do terminal portuário do Lago Maicá. Este resultado foi possível principalmente pela pressão que os coletivos indígenas e quilombolas fizeram contra a construção do empreendimento, destacando-se as manifestações
20 Referente ao Inquérito Civil n. ${ }^{\circ} 1.23 .002 .000432 / 2004-82$. 
coletivas de mulheres indígenas e quilombolas, contrárias à construção do porto.

A atual modalidade de exploração territorial e dos corpos indígenas, da monocultura da soja, é entendida como o auge do esgotamento dos recursos naturais e da pressão contra os indígenas, quilombolas e povos tradicionais. Em relatos de indígenas durante o trabalho de campo, a categoria escravidão é acionada em relação às transformações da paisagem e ao consequente esbulho territorial generalizado, incluindo todos os povos etnicamente diferenciados que construíram sua história na região e que estão cada vez mais pressionados pelo "grande cerco de paz" (Lima 1995), imposto pelos programas de Estado sobre esses grupos, invisibilizando suas estratégias de reprodução social e cultural.

\section{Considerações finais}

Neste texto tentei apresentar dois movimentos antagônicos se organizando: por um lado, o fortalecimento do empresariado do agronegócio com a expansão da soja e, por outro, a organização e a articulação dos movimentos indígenas no Baixo Tapajós e no Baixo Amazonas. As categorias violência e relações de poder são chaves para compreender todo o processo esboçado nos itens anteriores deste texto. As estratégias de resistência também envolvem disputas por classificações sociais, processos de disseminação e de fortalecimento das identidades indígenas na região, bem como disputas históricas, sociais e econômicas. A violência aqui não é vista como uma categoria abstrata, mas possui um sentido histórico, social e concreto, seja na ação do Estado, seja no político e econômico. A violência é tratada aqui a partir da compreensão de que as histórias de vida imbricadas na violência fazem parte da história da nação (Das 2007).

Com uma narrativa embasada na ideia de "desenvolvimento", de "civilização" da região e de "trazer o progresso", os novos agentes econômico-empresariais forçam, por meio de uma expropriação continuada, uma reorganização das relações sociais, com a intensificação das tensões intra e intergrupos e dos conflitos socioambientais, pela exploração e apropriação dos recursos ambientais renováveis. Trata-se de uma frente de expansão do agronegócio sobre os territórios de ocupação tradicional, reivindicados como terras indígenas e quilombolas pelos sujeitos coletivos que lutam pelo seu reconhecimento, demarcação e titulação junto ao Estado brasileiro.

As investidas violentas perpetradas pelos produtores de soja podem ser percebidas também por meio de repertórios discursivos, como o reforço do preconceito e o racismo contra os próprios indígenas e quilombolas, que também estão presentes na região, o que facilitou o processo de expropriação de territórios. Esta é uma estratégia que ocorre desde o período colonial, quando os europeus tomaram territórios e exterminaram diversos grupos étnicos, com técnicas de desarticulação de grupos, ao fomentar conflitos prévios.

Assim como o empresariado do agronegócio articula suas bases no setor político, os movimentos indígenas se articulam cada vez mais no plano político de representação. Nas eleições de 2020, foi lançada a primeira chapa de mandato 
coletivo de mulheres indígenas e quilombolas em Santarém. A chapa para a vaga de vereadora, pelo Partido Socialismo e Liberdade (PSOL), foi composta por Claudiana Lírios, Luana Kumaruara, Tati Picanço e Alessandra Caripuna. Embora essas lideranças não tenham sido eleitas e não tenham contado com um apoio efetivo e incisivo do partido, a campanha foi corajosa. As candidatas percorreram vários territórios indígenas apresentando o programa da campanha e fazendo um trabalho de base. Tais ações foram realizadas no contexto da pandemia de covid-19, o que exigiu um esforço maior para manter a segurança da saúde dos envolvidos.

Ter acesso à terra e aos direitos não significa apenas possuir um bem específico, mas a possibilidade de reprodução social, cultural, política e econômica. É assumir o compromisso e o protagonismo de sua história - indígena. Deste modo, o sentimento de pertença a um grupo e seus interesses, sejam econômicos ou políticos, é um aspecto da composição da etnicidade em questão.

Em 15 de dezembro de 2021, o Cita foi homenageado com o título de honra ao mérito como instituição de representação dos povos indígenas do Baixo Tapajós ${ }^{21}$. Quem recebeu o prêmio foi a atual coordenadora, Auricélia Arapiun, que enfatizou as contradições das práticas de Estado, engendrado pelo Legislativo, em discurso que circulou nas redes sociais ${ }^{22}$. Auricélia destacou que o Cita foi a única organização homenageada no mesmo espaço onde haviam sofrido racismo, com a criação da "Comissão especial": "e hoje estamos aqui, passando por cima do racismo!”, disse a liderança.

\section{$* * *$}

Dedico este texto aos mais de 624 mil mortos no Brasil por covid-19 e pela omissão dos governantes (apesar da existência do SUS) no combate à pandemia, dentre eles: indígenas, não indígenas e os meus parentes próximos (pai, madrasta e tias, em Manaus, no início do ano de 2021) que também tiveram suas histórias, corpos e subjetividades forjados nos regimes de memória da violência nos interiores da Amazônia.
21 Fonte: https://sapl. santarem.pa.leg.br/media/ sapl/public/materialegislativa/2021/18420/proj_dec_ leg_35 02_2021_j_tapajos_out_ honra_merito_cita.pdf 22 Fonte: transcrição de vídeo enviado via WhatsApp, gravado em dezembro de 2021. 


\section{Referências}

Alarcon, Daniela Fernandes. 2019. O retorno da terra: as retomadas na aldeia tupinambá da Serra do Padeiro, Sul da Bahia. São Paulo: Elefante.

Almeida, Silvio. 2020. Racismo estrutural. São Paulo: Jandaíra.

Almeida, Alfredo Wagner Berno de. 2010. "Agroestratégias e desterritorialização: direitos territoriais e étnicos na mira dos estrategistas dos agronegócios". In Capitalismo globalizado e recursos territoriais: fronteiras da acumulação no Brasil contemporâneo, 101-43. Rio de Janeiro: Lamparina.

Arantes, Luana Lazzeri. 2019. "Reflexões sobre processos de constituição do movimento indígena no Baixo Tapajós a partir de narrativas femininas". Revista Ciências da Sociedade 3 (5): 92-117. Acesso 10 set. 2019. http://www.ufopa.edu.br/portaldeperiodicos/index.php/revistacienciasdasociedade/issue/view/31.

Bates, Henry Walter. 1979. Um naturalista no rio Amazonas. Belo Horizonte: Itatiaia; São Paulo: Edusp.

Beltrão, Jane Felipe. 2014. "Pertenças, territórios e fronteiras entre os povos indígenas dos rios Tapajós e Arapiuns versus o Estado brasileiro". Antares: Letras e Humanidades 5: 5-27. Acesso 10 nov. 2018. http://www.ucs.br/etc/revistas/index.php/antares/ article/view/2544/ 1489.

Cardoso, Luana da Silva. 2019. "Memorial de uma liderança indígena: a construção política da trajetória... Driblando as armadilhas da colonização". Tellus 39: 293-307. Acesso 10 fev. 2020. https://www.tellus.ucdb.br/tellus/article/view/634.

Comissão Interamericana de Direitos Humanos - CIDHa. 2018. Observações preliminares da visita in loco da CIDH ao Brasil. Acesso 15 nov. 2018. https://www.oas.org/es/ cidh/prensa/ comunicados/2018/2380Pport.pdf.

Comissão Interamericana de Direitos Humanos - CIDHb. 2018. "CIDH conclui visita ao Brasil". Comunicado de imprensa. Organização dos Estados Americanos - OEA, 12 nov. 2018. https://www.oas.org/pt/cidh/prensa/notas/2018/238.asp.

Costa, Solange Maria Gayoso da. 2012. "Grãos na floresta: estratégia expansionista do agronegócio na Amazônia". Tese de doutorado, Universidade Federal do Pará, Belém. Acesso 20 dez. 2019. http://repositorio.ufpa.br/jspui/handle/2011/11157.

Costa, Solange Maria Gayoso da. 2019. "Violência, discriminação, racismo e conflitos envolvendo os povos Indígenas do Baixo Tapajós”. Temporalis 38: 87-100. Acesso 18 set. 2020. https://periodicos.ufes.br/temporalis/article/view/24212.

Das, Veena. 2007. Life and Words: Violence and the Descent into the Ordinary. Berkeley, University of California Press.

Del Arco, Diego Pérez. 2017. "As comunidades quilombolas de Santarém/PA e o Porto de Maicá: os efeitos sociais de um empreendimento anunciado". Trabalho de Conclusão de Curso de Graduação em Antropologia/Universidade Federal Fluminense. Acesso 18 set. 2020. https://app.uff.br/riuff/bitstream/handle/1/6894/TCC\%20 Final\%20(1).pdf;jsessionid=3A9DC9A76B22B936F33F1A4A827E5F7E?sequence=1

Fanon, Frantz. 1968. Os Condenados da Terra. Rio de Janeiro, RJ: Editora Civilização Brasileira.

Fundação Nacional do Índio - Funai. 2001. Relatório de viagem ao rio Tapajós elaborado por Rita Heloisa de Almeida em atendimento ao artigo $3^{\circ}$ da Portaria $n^{\circ} 84$ de 
Katiane Silva

31 de janeiro de 2001, publicada pelo DOU de 02 de fevereiro de 2001, e ao artigo da Portaria n478/PRES/31 de maio de 2001, DOU de 07 de junho de 2001. Brasília.

Gupta, Akhil. 2015. "Fronteras borrosas: el discurso de la corrupción, la cultura de la política y el estado imaginado". In Antropología del Estado, orgs. Philip Abrams, Akhil Gupta, e Timothy Mitchel. México: Fondo de Cultura Económica.

Ioris, Edviges Marta. 2014. Uma floresta de disputas: conflitos sobre espaços, recursos e identidades sociais na Amazônia. Florianópolis: Editora da UFSC.

loris, Edviges Marta. 2018. "Memory regimes, struggles over resources and ethnogenesis in the Brazilian Amazon". Vibrant: Virtual Brazilian Anthropology 15: 1-23. Acesso 18 set. 2020. https://www.scielo.br/pdf/vb/v15n2/1809-4341-vb-15-02-e152405.pdf.

Ioris, Edviges Marta. 2019. "Chamado do pajé: regimes de memória, apagamentos e protagonismo indígena no Baixo Tapajós". Revista Ciências da Sociedade 5: 39-60. Acesso 18 set. 2020. http://www.ufopa.edu.br/portaldeperiodicos/index.php/revistacienciasdasocieda de/article/view/984/510.

Lima, Antônio Carlos de Souza. 1995. Um grande cerco de paz: poder tutelar, indianidade e formação do Estado no Brasil. Petrópolis: Vozes.

Lima, Deborah Magalhães. 1999. "A construção histórica do termo caboclo: Sobre estruturas e representações sociais no meio rural amazônico". Novos Cadernos Naea 2: 2-32. Acesso 29 mar. 2020. https://periodicos.ufpa.br/index.php/ncn/article/ viewArticle/107.

Lima, Leandro Mahalem de. 2015. "No Arapiuns, entre verdadeiros e -ranas: sobre os espaços, as lógicas, as organizações e os movimentos do político". Tese de doutorado, Universidade de São Paulo, São Paulo. Acesso 10 set. 2019. https://www.teses. usp.br/teses/disponiveis/8/ 8134/tde-06072015-122321/pt-br.php.

Lima, Leandro Mahalem de. 2019. "Pajelança nas adjacências do Rio Amazonas: dimensões sociopolíticas e cosmológicas". Revista Ciências da Sociedade 3(5): 61-91, Santarém, jan.-jun. 2019. Acesso 18 set. 2020. http://www.ufopa.edu.br/portaldeperiodicos/index.php/revista cienciasdasociedade/article/view/985.

Menezes, Thereza Cristina Cardoso. 2020. "Environmental Governance and Regularization of Land Ownership: development and multiple territorial dynamics in the Amazon". Vibrant: Virtual Brazilian Anthropology 17: 1-18. Acesso 12 abr. 2020. https:// www. scielo.br/j/vb/a/PfbGBdyzSzkkQ7bXbd8HTSw/?lang=en.

Ministério Público Federal - MPF. 2018. Ação Civil Pública com pedido de tutela provisória de urgência. Santarém. Acesso 18 set. 2020. http://www.mpf.mp.br/pa/ sala-de-imprensa/documentos/2018/acao_mpf_identificacao_delimitacao_territorio_munduruku_planalto_santareno_pa_maio_2018.pdf/view.

O’Dwyer, Eliane Cantarino, e Katiane Silva. 2020. "Anthropological practices, inter-group conflicts and shared colonial experiences in a regional context of the Lower Amazon". Vibrant: Virtual Brazilian Anthropology 17. Acesso 18 set. 2020. https:// www.scielo.br/j/vb/a/9h 8zvT DmdkVf5mZWkpHpx6F/?lang=en.

Oliveira Filho, João Pacheco de. 1999. Ensaios em antropologia histórica. Rio de Janeiro: Editora UFRJ.

Pacheco de Oliveira, João. 2016. "Narrativas e imagens sobre povos indígenas e a Amazônia: uma perspectiva processual da fronteira". In O nascimento do Brasil e outros ensaios: "pacificação", regime tutelar e formação de alteridades, 161-91. Rio de Janeiro: Contra Capa. 
Katiane Silva

Papavero, Nelson, e William L. Overal, orgs. 2011. Taperinha. Belém: Ed. Museu Paraense Emílio Goeldi.

Peixoto, Rodrigo; Karl Arenz, e Kércia Figueiredo. 2012. “O Movimento Indígena no Baixo Tapajós: etnogênese, território, Estado e conflito”. Novos cadernos NAEA. 15: 279-313. Acesso 18 set. 2020. https://periodicos.ufpa.br/index.php/ncn/article/ view/719.

Roca, Andrea. 2014. Os sertões e o deserto: imagens da "nacionalização" dos índios no Brasil e na Argentina, na obra de J. M. Rugendas (1802-1858). Rio de Janeiro: Garamond.

Roca, Andrea. 2019. "As imagens dos cronistas-viajantes Thévet, Staden e Léry, século XVI, no Relatório da 'CPI Funai-INCRA 2', século XXI”. In Imigração e cultura material: coisas e pessoas em movimento, orgs. Patricia Reinheimer, Nathanael Araújo, e Miriam Santos. São Leopoldo: Oikos. Acesso 18 set. 2020. http://oikoseditora.com.br/ files/Imigra\%C3\%A7\%C3\%A30\%20e \%20cultura\%20material\%20-\%20e-book.pdf.

Rosa, Marlise Mirta. 2016. "A centralidade da questão territorial nas ofensivas legislativas contra os povos indígenas”. Estudos Sociedade e Agricultura 24 (1): 183-208. Acesso 18 set. 2020. https://revistaesa.com/ojs/index.php/esa/article/view/549.

Santarém. 2018. Requerimento ${ }^{\circ}$ 1.269/2018, que dispõe sobre a criação de uma comissão especial de estudos parlamentares sobre a proliferação de grupos étnicos no município de Santarém - PA. Acesso 12 jan. 2020. https://sapl.santarem.pa.leg.br/ materia/7993.

Santarém. 2019a. Ata da Vigésima Quinta Sessão Ordinária do Primeiro Período da Terceira Sessão Legislativa da Décima Oitava Legislatura, realizada no dia dezesseis de abril do ano de dois mil e dezenove. Acesso 12 jan. 2020. https://sapl.santarem. pa.leg.br/materia/9097.

Santarém. 2019b. Ata da Quadragésima Sessão Ordinária do Segundo Período da Terceira Sessão Legislativa da Décima Oitava Legislatura, realizada no dia três de junho do ano de dois mil e dezenove. Acesso 12 jan. 2020. https://sapl.santarem.pa.leg.br/ materia/10141.

Santarém. 2019c. Ata da Décima Segunda Sessão Ordinária do Segundo Período da Terceira Sessão Legislativa da Décima Oitava Legislatura, realizada no dia nove de setembro do ano de dois mil e dezenove. Acesso 12 jan. 2020. https://sapl.santarem. pa.leg.br/materia/10832.

Schmink, Marianne, e Charles H. Wood. 2012. Conflitos e a formação social da Amazônia. Belém: Editora UFPA.

Silva, Katiane. 2015. Parente é serpente: ambientalismo, conflitos sociais e uso dos recursos naturais no Auati-Paraná, Amazonas. Tese de Doutorado, Museu Nacional/ Universidade Federal do Rio de Janeiro, Rio de Janeiro. Acesso 15 mar. 2020. http:// objdig.ufrj.br/72/teses/827884.pdf.

Smith, Herbert Huntingdon. 1879. Brazil: The Amazon and the Coast. New York: Charles Scribner's Sons. Acesso 6 nov. 2019. https://archive.org/details/brazilamazon scoa00smit.

Steward, Corina. 2007. "From colonization to 'environmental soy': a case study of environmental and socio-economic valuation in the Amazon soy frontier". Agriculture and Human Values 24: 107-22. Acesso 16 out. 2020. https://link.springer.com/article/10.1007/ s10460-006-9030-4.

Terra de Direitos. 2015. Estudo de caso da cadeia dominial de propriedades de sojiculto- 
Katiane Silva

res em Terra Indígena do povo Munduruku em Santarém, Estado do Pará. Relatório. Santarém.

Vaz Filho, Florêncio Almeida. 2010. "A emergência étnica de povos indígenas no Baixo Tapajós”. Tese de Doutorado, PPGCS /Universidade Federal da Bahia, Salvador. Acesso 15 mar. 2020. https://repositorio.ufba.br/handle/ri/33752

Vaz Filho, Florêncio Almeida. 2013. "Os conflitos ligados à sobreposição entre terras indígenas e a Resex Tapajós-Arapiuns no Pará”. Ruris 7: 143-83. Acesso 15 out. 2019. https://www.ifch. unicamp.br/ojs/index.php/ruris/article/view/1886.

Wolf, Eric. 2003. Antropologia e poder: contribuições de Eric R. Wolf, org. Bela Feldman-Bianco, e Gustavo Lins Ribeiro. Brasília: Editora Universidade de Brasília; São Paulo: Editora Unicamp. 